\title{
Parasympathetic Dysfunction in Black African Patients with Heart Failure: A Cross-Sectional Study in Sub-Saharan Africa
}

\section{Ba Hamadou ${ }^{1,2 *}$, Sylvie Ndongo Amougou1,3, Ismaila Daouda4, Chris Nadège Nganou-Gnindjio1,2, Liliane Mfeukeu-Kuate1,2, Jérôme Boombhi'1,4,5, Ahmadou Musa Jingi1 (i), Alain Menanga1,4,5, Samuel Kingue ${ }^{1,4,5}$}

${ }^{1}$ Department of Medicine and Specialties, Faculty of Medicine and Biomedical Sciences, University of Yaoundé I, Yaoundé, Cameroon

${ }^{2}$ Cardiology Unit, Central Hospital of Yaoundé, Yaoundé, Cameroon

${ }^{3}$ Cardiology Unit, University Teaching Hospital of Yaoundé, Yaoundé, Cameroon

${ }^{4}$ Faculty of Medicine and Biomedical Sciences, University of Yaoundé I, Yaoundé, Cameroon

${ }^{5}$ Cardiology Unit, Medicine B, General Hospital of Yaoundé, Yaoundé, Cameroon

Email: ^drhamadouba@yahoo.fr, jingiahmadoumusa@yahoo.co.uk

How to cite this paper: Hamadou, B., Amougou, S.N., Daouda, I., Nganou-Gnindjio, C.N., Mfeukeu-Kuate, L., Boombhi, J., Jingi, A.M., Menanga, A. and Kingue, S. (2020) Parasympathetic Dysfunction in Black African Patients with Heart Failure: A Cross-Sectional Study in Sub-Saharan Africa. World Journal of Cardiovascular Diseases, 10, 178-187.

https://doi.org/10.4236/wjcd.2020.104018

Received: February 29, 2020

Accepted: April 17, 2020

Published: April 20, 2020

Copyright $\odot 2020$ by author(s) and Scientific Research Publishing Inc. This work is licensed under the Creative Commons Attribution International License (CC BY 4.0).

http://creativecommons.org/licenses/by/4.0/

(c) (i) Open Access

\begin{abstract}
Background: Heart Failure (HF) is a major public health problem worldwide. Neurohormonal changes associated with HF are current therapeutic targets. The parasympathetic system in HF has not been well studied especially in black Africans. Aim: This study aimed to report on the prevalence and determinants of parasympathetic dysfunction in patients with heart failure in sub-Saharan Africa. Methods. We conducted a cross-sectional study between December 2017 and April 2018 in the outpatient and inpatient departments in two teaching hospitals in Yaounde-Cameroon. Cases were patients with HF matched with controls without HF according to age, sex, and risk factors (hypertension, diabetes, and obesity). We assessed the parasympathetic function via the Deep Breathing Test using an electrocardiograph. Results. We recruited 35 patients in each group. The mean age was $57 \pm 11.68$ years. Vagal dysfunction was seen in $51.4 \%$ of cases and $11.4 \%$ of controls (aOR: 10.1 [95\% CI: $2.7-38.3$ ] $\mathrm{p}=0.001$ ). This risk increased with the severity of HF-aOR: 11.8, [95\% CI: $1.8-77.9$ ], $\mathrm{p}=0.01$ for dyspnea stage III-IV, and aOR: 9.27, [95\% CI: $1.3-65.3$ ], $\mathrm{p}=0.025$ ) for HF with reduced Ejection fraction. This risk was not associated with the classic cardiovascular risk factors. Conclusion: Parasympathetic dysfunction as assessed with the Deep Breathing Test was seen in over half of the patients with HF and this was associated with the severity and type of HF.
\end{abstract}


Keywords

Heart Failure, Parasympathetic Dysfunction, Heart Rate Variability, Deep Breathing Test

\section{Introduction}

Heart failure (HF) is the inability of the heart to provide blood flow necessary for the needs of the body, both at rest and during exercise, without the expense of raised filling pressures. It is a public health problem worldwide with increasing prevalence due to the aging of the population [1]. It is associated with high morbi-mortality and high health expenditure [2] [3] [4]. About fifty percent of patients with HF die suddenly, while the other half die due to the progression of the disease to the terminal stage [5]. The cause of sudden death is often due to arrhythmia as a result of autonomic dysfunction [6]. The autonomic nervous system (ANS) is made up of sympathetic and parasympathetic branches. They play an important role in the progression of heart failure. The ANS is the first neuro-hormonal response mechanism in HF. This response in HF is characterized by sympathetic hyperactivity, and parasympathetic dysfunction [6]. This neuro-hormonal response is initial compensatory mechanisms with long term adverse effects on the heart. La Rovere et al. [7] demonstrated that parasympathetic dysfunction and the loss of heart rate variability predicted poor outcome in patients with HF complicating myocardial infarction. Boombhi et al. [8] demonstrated a reduction of heart rate variability in a group of patients with HF. Most studies on autonomic dysfunction in HF have focused on the sympathetic system. Recently, vagal stimulation as a therapeutic option has highlighted the importance of the parasympathetic system in the pathogenesis of HF [9] [10].

Data on the prevalence and determinants of parasympathetic dysfunction in $\mathrm{HF}$ are lacking in black Africans residing in sub-Saharan Africa. This study aimed to report on the prevalence and determinants of parasympathetic dysfunction in patients with heart failure in sub-Saharan Africa.

\section{Methods}

Study design and Setting. We carried out a cross-sectional study in two University teaching hospitals in Yaounde-General Hospital (YGH) and Central hospital (YCH). This study was carried out between December 2017 and April 2018. Yaounde is the political capital of Cameroon, sub-Saharan Africa. The population is over 2 million inhabitants. The YGH and $\mathrm{YCH}$ are first and second category hospitals that serve as teaching hospitals for both undergraduate and graduate students.

Study participants. These were prospectively recruited from the out-patient department and the hospitalization units of the hospitals. We recruited consenting patients (cases) aged $\geq 18$ years of both sexes with an established diagno- 
sis of heart failure (clinical and echocardiographic criteria) and who were receiving regular care in the teaching hospitals. Sex and age ( \pm 5 years) matched controls with similar risk factors were also recruited from the out-patient consultation. We excluded patients with significant arrhythmia-Atrial fibrillation, atrial flutter, frequent premature supraventricular and ventricular ectopic beats, and ventricular tachycardia. We also excluded current smokers.

Variables and measurements. After signing the informed consent form, we performed a face-to-face interview for both cases and controls. We collected data sociodemographic data (age, sex, profession, marital status), cardiovascular risk factors (hypertension and diabetes). Symptoms of left and right heart failure were collected [11]. We classified dyspnea according to the New York Heart Association grade. Data on cardiac ultrasound was collected from the patients' records (cases). We classified heart failure as reduced ejection fraction (HFrEF) when the left ventricular ejection fraction (LVEF) was $<40 \%$, mid-range (HFmEF) when the LVEF was $40 \%$ - 49\%, and preserved ejection fraction (HFpEF) when the LVEF was $\geq 50 \%$. Data on the treatment of heart failure was also collected from the patient records. We measured the resting heart rate by auscultating the heart. The blood pressure was measured after 10 minutes of rest with an electronic blood pressure device OMRON HEM-7200 E2. A standard cuff size was used. Average of two blood pressure readings > 140/90 mmHg taken 5 minutes apart were considered elevated. We measured the height $(\mathrm{m})$ with a stadiometer, and the weight $(\mathrm{kg})$ in light clothing and no shoes with a Seca ${ }^{\circledR}$ scale balance-SECA 877, Classe III. We calculated the Body Mass Index (BMI) as the weight $(\mathrm{kg}) /$ height $^{2}$. Normal weight was defined as BMI $18-24.9 \mathrm{~kg} / \mathrm{m}^{2}$, overweight as BMI $25-29.9 \mathrm{~kg} / \mathrm{m}^{2}$, and obesity as BMI $\geq 30$ $\mathrm{kg} / \mathrm{m}^{2}$. We performed a complete physical examination in search of signs of heart failure [11].

We then performed a resting 12 lead ECG (cases and controls) with an HP PageWriter $100^{\circledR}$ electrocardiograph using standard technique. This was to rule out significant arrhythmia.

Finally, we performed a deep breath test (DBT) for both cases and controls to assess for parasympathetic dysfunction. The DBT consists in recording the ECG while the patients slowly take in a deep breath for over 5 seconds, and then breaths out calmly for over 5 seconds. The total recording time of the DBT was one minute. The D1, D2, and D3 leads were considered for the DBT. The RR interval between the QRS complexes was measured with a graduated ECG rule. Six longest and six shortest RR intervals were identified (Figure 1). The average of the six longest RR and the six shortest RR intervals were noted. We then calculated the $\mathrm{E} / \mathrm{I}$ ratio as the longest mean $\mathrm{RR}$ interval divided by the shortest RR interval. Parasympathetic dysfunction was defined as an E/I ratio less than normal for age [12].

Study size and statistical analysis. A convenient sample of all eligible participants was considered for this study. Data were analyzed using the software IBM-Statistical Package for Social Sciences (IBM-SPSS) 21.0. The Shapiro Wilk 


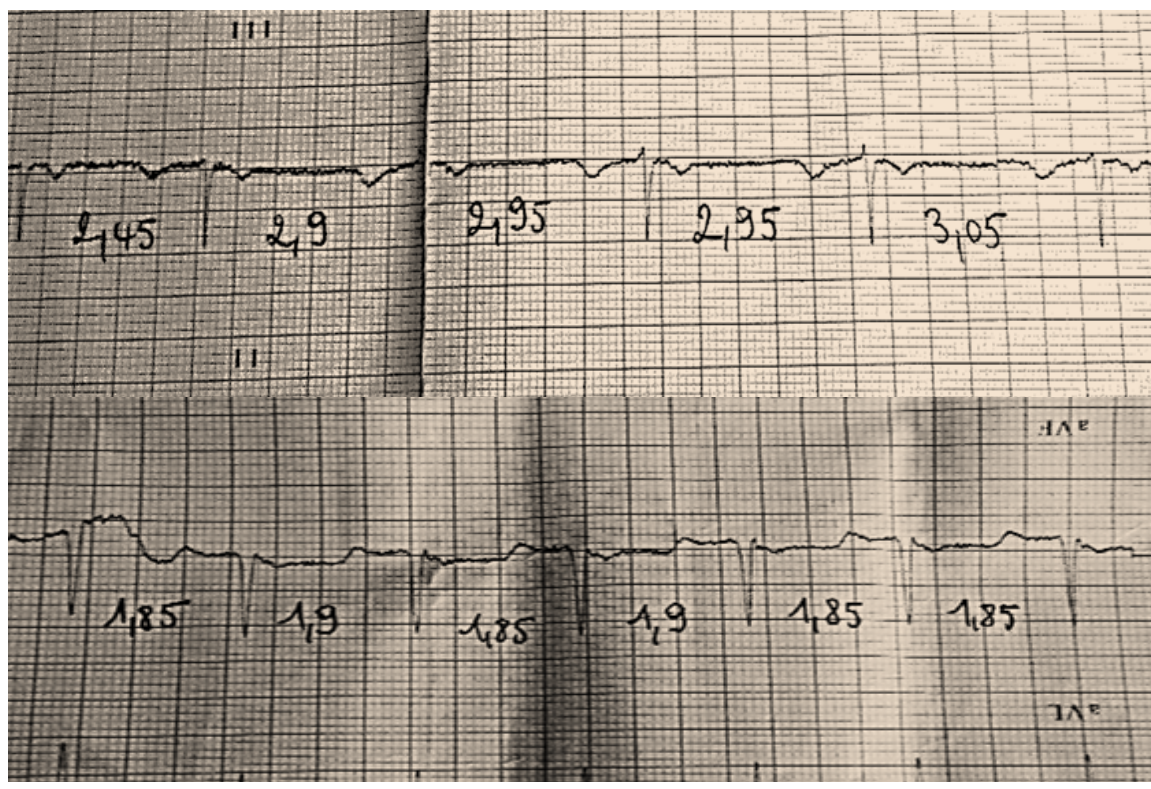

Figure 1. Assessing parasympathetic dysfunction with a deep breathing test in patients with heart failure. The upper panel shows a patient with heart failure without vagal dysfunction, while the lower panel shows a patient with heart failure and vagal dysfunction.

test was used to evaluate for normality of the data. Qualitative data are presented as counts and percentages. A comparison between qualitative data was assessed with the Chi-squared test or Fisher exact test where appropriate. Quantitative variables are presented as means (SD) or median (IQR). Quantitative data were compared using the Student t-test or the Wilcoxon signed-rank test where appropriate. A p-value $<0.05$ was considered statistically significant for the observed differences or associations.

Ethical statement. Ethical clearance was obtained from the Institutional Review Board of the Faculty of Medicine and Biomedical Sciences, University of Yaounde1. Administrative authorization was obtained from the local hospital administration. We carried out this work following the declarations of Helsinki. We report this work following the STandard for Reporting OBservational studies in Epidemiology (STROBE) checklist.

\section{Results}

Participants. A total of 162 patients were approached, of whom 4 refused to participate. Fifty-one patients were excluded for non-fulfilling the inclusion criteria. Of the 107 eligible patients, 44 had HF (9 excluded for lack of echocardiogram data). The 35 patients with HF included in the analysis were matched with 35 controls according to sex, age, and cardiovascular risk factors (Figure 2).

Descriptive data: The mean age was $57.3 \pm 11.7$ years, and ranged from 30 to 80 years. The male to female sex ratio was 0.94 . In both groups, $42(60 \%)$ were obese, $12(17.1 \%)$ had diabetes, and $54(77.1 \%)$ had hypertension. The signs and symptoms of heart failure are shown in Table 1. Ten patients (28.6\%) had severe dyspnea (Stage 3 and 4). All cases (100\%) had left heart failure, of whom 14 


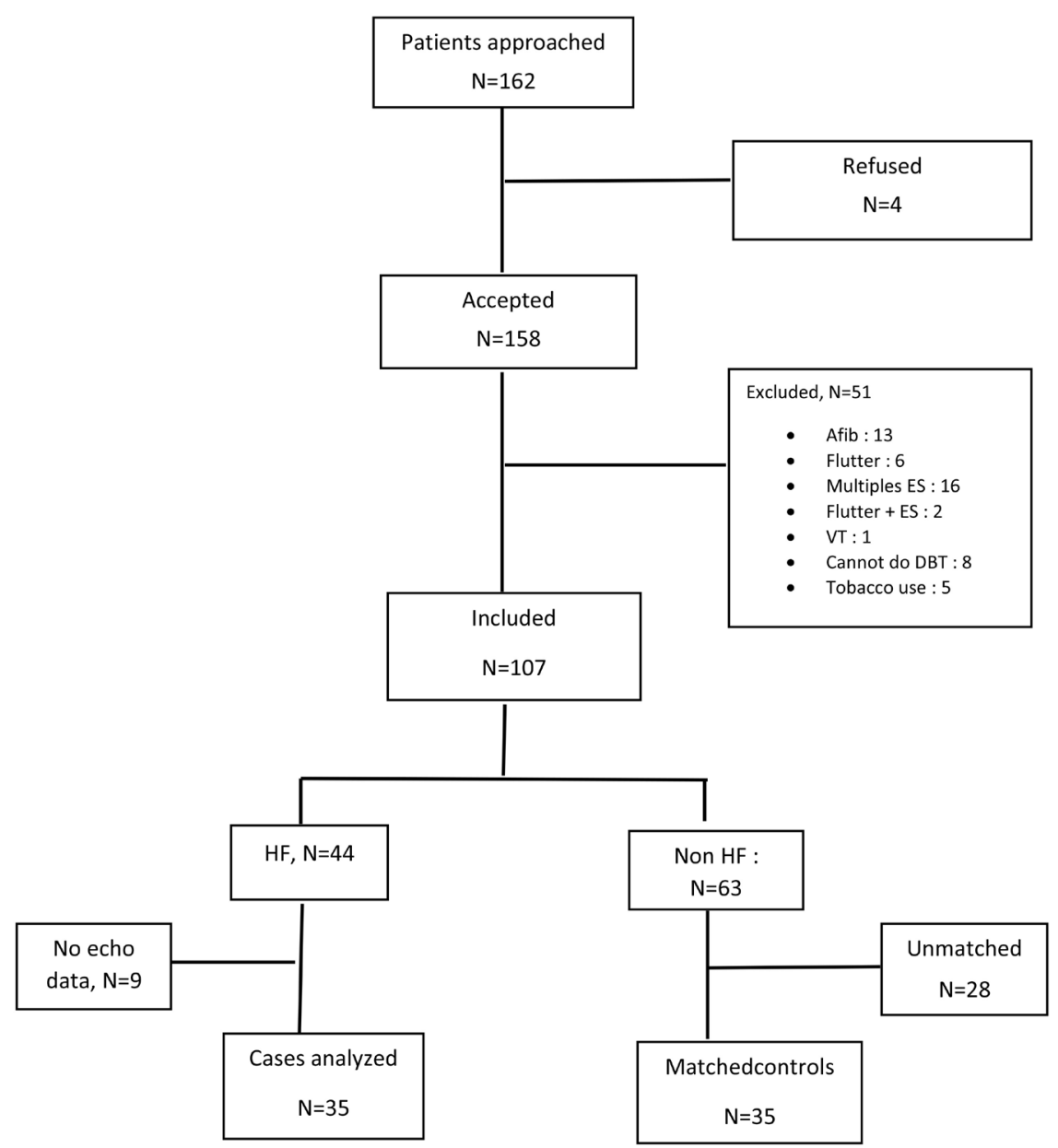

Figure 2. Flow chart of the participants (Afib: Atrial fibrillation; ES: Extra-systoles; VT: Ventricular tachycardia; DBT: Deep Breath Test).

Table 1. Symptoms, signs, and treatment in the heart failure group.

\begin{tabular}{lcc}
\hline \multicolumn{1}{c}{ Variables } & Frequency $(\mathrm{n})$ & Percentage (\%) \\
\hline Dyspnea grade & 0 & 0 \\
I & 25 & 71.4 \\
II & 8 & 22.9 \\
III & 2 & 5.7 \\
IV & & \\
Signs of heartfailure & 2 & 5.7 \\
Lung crepitations & 2 & 5.7 \\
Pleural effusion & 0 & 0 \\
Galop rythme & 3 & 8.5 \\
Hepatomegaly & 3 & 8.5 \\
Harzer's sign & 4 & 11.4 \\
Hepato-jugular reflux & 7 & 23.3 \\
Pedaledema & 1 & 2.9 \\
Jugular veinous distension & &
\end{tabular}




\section{Continued}

Treatment of heartfailure

Angiotensin Receptor Blocker

Angiotensin-Converting Enzyme Inhibitor

2

Beta-blocker

Diuretics

Anti-coagulants

Anti-arrhythmics

$3 \quad 8.6$

$31 \quad 88.6$

$8 \quad 22.9$

3
51.4

6

6

8.6

(40\%) also had signs of right heart failure. Of those with HF, 12 (34.3\%) had LV ejection fraction $<40 \%$. Four patients $(11.4 \%)$ were not on treatment for heart failure. Diuretics were the most frequently prescribed medicines (Table 1).

Outcome data and main results. Patients with HF had a significantly higher heart rate and blood pressure. Also, patients with HF had significantly lower maximum RR and E/I ratio (Table 2). The determinants of vagal dysfunction are shown in Table 3. Vagal dysfunction was seen in 18 (51.4\%) cases with HF and 4 (11.4\%) controls without HF (OR: 8.2, [95\% CI: 2.4 - 28.2], $\mathrm{p}=0.001$ ). The risk was significantly higher in those with HFrEF (OR: 9.4, [95\% CI: 1.6 - 53.6], $\mathrm{p}=$ 0.012 ). There was a non-significant higher risk in those with diabetes or obesity. This risk was not associated with sex and hypertension.

After adjusting for Diabetes and Obesity, independent predictors of vagal dysfunction were Heart failure (aOR: 10.1 [95\% CI: 2.7 - 38.3], $\mathrm{p}=0.001$ ), the severity of HF (aOR: 11.8, [95\% CI: $1.8-77.9$ ], $\mathrm{p}=0.01$ for dyspnea stage III IV), and HFrEF (aOR: 9.27, [95\% CI: $1.3-65.3$ ], $\mathrm{p}=0.025$ ).

\section{Discussion}

We carried out a cross-sectional study to assess for the prevalence and determinants of parasympathetic dysfunction (PSD) in patients with heart failure using the Deep Breath Test (DBT) in a group of black African patients with Heart Failure (HF) in sub-Saharan Africa. Compared to those without HF, parasympathetic dysfunction was significantly higher in those with HF. Half of the patients with HF had parasympathetic dysfunction, and this was associated with the severity of the disease.

Data on parasympathetic dysfunction in black Africans with heart failure are lacking to the best of our knowledge. Also, many studies on autonomic dysfunction in HF have focused on the sympathetic system. There are several technics in assessing autonomic function. The DBT is specially designed to assess the parasympathetic system [12]. In a group of 25 patients with stage 3 and 4 HF (compared with 21 normal subjects) who underwent 15-minutes of spectral analysis, Saul et al. [13] found out that all the components of spectral power were decreased especially for domain frequencies $>0.04 \mathrm{~Hz}$. They showed that the vagal tone was reduced, associated with relative preservation of sympathetic modulation in patients with congestive HF. Casolo et al. [14] showed a reduction in 
Table 2. Mean values of hemodynamic and parasympathetic function parameters.

\begin{tabular}{cccc}
\hline Variables & Heart failure & Non-Heart failure & p-value \\
\hline Heart rate (beats/minute) & $90.3 \pm 14.5$ & $77.8 \pm 11.7$ & $<0.001$ \\
Systolic Blood Pressure $(\mathrm{mmHg})$ & $133.3 \pm 11.3$ & $124.3 \pm 8.8$ & $<0.001$ \\
Diastolic Blood Pressure $(\mathrm{mmHg})$ & $76.1 \pm 10.5$ & $70.1 \pm 7.3$ & 0.007 \\
Body Mass Index $\left(\mathrm{kg} / \mathrm{m}^{2}\right)$ & $31.4 \pm 5.2$ & $30.5 \pm 4.9$ & 0.5 \\
Maximum RR $(\mathrm{mm})$ & $21.3 \pm 4.1$ & $25.2 \pm 4.8$ & 0.001 \\
Minimum RR $(\mathrm{mm})$ & $19.2 \pm 3.5$ & $20.4 \pm 3.1$ & 0.134 \\
E/I ratio & $1.11 \pm 0.1$ & $1.23 \pm 0.1$ & $<0.001$ \\
\hline
\end{tabular}

Table 3. Determinants of Parasympathetic dysfunction (PSD).

\begin{tabular}{|c|c|c|c|c|}
\hline Variable & PSD, n (\%) & No PSD, n (\%) & OR (95\% CI) & p-value \\
\hline \multicolumn{5}{|l|}{ Sex } \\
\hline Male & $13(34.2)$ & $25(65.8)$ & $1.3(0.5-3.7)$ & 0.585 \\
\hline Female & $9(28.1)$ & $23(71.9)$ & 1 & \\
\hline
\end{tabular}

Hypertension

$\begin{array}{ccccc}\text { Yes } & 16(29.6) & 38(70.4) & 0.7(0.2-2.3) & 0.553 \\ \text { No } & 6(37.5) & 10(62.5) & 1\end{array}$

Diabetes

$\begin{array}{ccccc}\text { Yes } & 6(50) & 6(50) & 2.6(0.7-9.3) & 0.136 \\ \text { No } & 16(27.5) & 42(72.5) & 1\end{array}$

Obesity

$\begin{array}{ccccc}\text { Yes } & 16(38.1) & 26(61.9) & 2.3(0.8-6.8) & 0.146 \\ \text { No } & 6(21.4) & 22(78.6) & 1 & \end{array}$

Heart failure

$\begin{array}{ccccc}\text { Yes } & 18(51.4) & 17(48.6) & 8.2(2.4-28.2) & 0.001 \\ \text { No } & 4(11.4) & 31(88.6) & 1 & \end{array}$

Severe HF (NYHA III/IV)

$\begin{array}{ccccc}\text { Yes } & 7(70) & 3(30) & 3(0.6-14) & 0.173 \\ \text { No } & 11(44) & 14(56) & 1 & \end{array}$

Type of HF

\begin{tabular}{lcccc} 
HFrEF & $10(83.3)$ & $2(16.7)$ & $9.4(1.6-53.6)$ & 0.012 \\
HFpEF & $8(34.8)$ & $15(65.2)$ & 1 & \\
\hline
\end{tabular}

PSD: Parasympathetic dysfunction. OR: Odds Ratio. CI: Confidence Interval. NYHA: New York Heart Association. HFrEF: Herat Failure with reduced Ejection Fraction. HFpEF: Heart Failure with preserved Ejection Fraction.

vagal tone in a group of 20 patients with congestive HF (stages 2, 3, and 4) compared with normal subjects after analysis of the time domain of the heart rate variability on 24-hour Holter ECG recordings. Several studies using spec- 
tral analysis, parameters of heart rate variability decreased with the severity of heart failure [15] [16] [17]. Our findings using DBT corroborates with these studies.

Overall, we observed a non-significant association of male sex with PSD. Huikuri et al. [18] observed that females are prone to PSD dysfunction. The mechanism of sex with the occurrence of PSD is not well known. Diabetes is a well-established risk for PSD [19]. We observed a non-significant higher risk of PSD in diabetics. Our study lacked power due to the small number of diabetics. After adjusting for diabetes, the odds of PSD increased suggesting a significant confounder in the occurrence of PSD in HF. Hypertension was not shown to be associated with PSD. However, this has been reported by several high powered studies with focus on hypertension [20]. We observed a non-significant higher risk of PSD in obese patients. Obesity is associated with PSD as reported by Karason et al. [21]. In our study, obesity is a significant confounder in the occurrence of PSD in HF.

Limitations. The main limitation of this study is the small sample size, resulting in loss of precision as shown by the large confident interval. Also, we did not take into account ischemic heart disease, which is also associated with autonomic dysfunction. Despite this limitation, this is the first study assessing parasympathetic dysfunction in a group of black Africans with heart failure. We have used a simple method (DBT) to assess for parasympathetic dysfunction in a low-income setting.

\section{Conclusion}

Parasympathetic dysfunction assessed with Deep Breath Test is frequent in black Africans with HF. This is associated with the clinical severity (NYHA class) of the disease and low ejection fraction (LVEF $<40 \%$ ). Further studies are needed in a larger sample of patients with HF using different methods to assess parasympathetic dysfunction in HF patients. This will help choose the optimal screening strategy.

\section{Acknowledgements}

We thank the support staff of the teaching hospitals for assisting with patient care.

\section{Funding}

None was received for this work.

\section{Authors' Contribution}

Conception and design: BH, SNA, ID, SK. Data collection: BH, SNA, ID, LMF, BJ, CNN, AM, JB. Data analysis and interpretation: BH, ID, SNA, AMJ, AM, SK. Drafting of the manuscript: BH, ID, SNN, AMJ. All the authors have read and approved the final version for publication. 


\section{Conflicts of Interest}

The authors declare no conflicts of interest regarding the publication of this paper.

\section{References}

[1] Van Riet, E.E., Hoes, A.W., Limburg, A., et al. (2014) Prevalence of Unrecognized Heart Failure in Older Persons with Shortness of Breath on Exertion. European Journal of Heart Failure, 16, 772-777. https://doi.org/10.1002/ejhf.110

[2] Maggioni, A.P., Dahlstrom, U., Filippatos, G., et al. (2013) EURObservational Research Programme: Regional Differences and 1-Year Follow-up Results of the Heart Failure Pilot Survey (ESC-HF Pilot). European Journal of Heart Failure, 15, 808-817. https://doi.org/10.1093/eurjhf/hft050

[3] Pousset, F., Isnard, R. and Komadja, M. (2005) L'insuffisance cardiaque: Problème de santé pubique. La Revue de Médecine Interne, 26, 843-844. https://doi.org/10.1016/j.revmed.2005.07.016

[4] Kingue, S., Dzudie, A., Menanga, A., Akono, M., Ouankou, M. and Muna, W. (2005) A New Look at Adult Chronic Heart Failure in Africa in the Age of the Doppler Echocardiography: Experience of the Medicine Department at Yaounde General Hospital. Annales de Cardiologie et d Angéiologie, 54, 276-283. https://doi.org/10.1016/j.ancard.2005.04.014

[5] Pousset, F. and Isnard Ret Komajda, M. (2003) Insuffisance cardiaque: Aspects épidémiologiques, cliniques et pronostiques. Encycl Méd Chir (Editions Scientifiques et Médicales Elsevier SAS, Paris, tous droits réservés), Cardiologie, 17 p.

[6] Dzau, V.J., Colucci, W.S., Hollenberg, N.K. and Williams, G.H. (1981) The Relation of the Renin-Angiotensin-Aldosterone System to Clinical State in Congestive Heart Failure. Circulation, 63, 645-651. https://doi.org/10.1161/01.CIR.63.3.645

[7] La Rovere, M.T., Bigger, J.T., Marcus, F.I., Mortara, A. and Schwartz, P.J. (1998) Baroreflex Sensitivity and Heart-Rate Variability in Prediction of Total Cardiac Mortality after Myocardial Infarction. ATRAMI (Autonomic Tone and Reflexes After Myocardial Infarction) Investigators. The Lancet, 351, 478-484. https://doi.org/10.1016/S0140-6736(97)11144-8

[8] Boombhi, J., Menanga, A. and Nkoke, C. (2016) Variabilité sinusale chez un groupe de sujets en Insuffisance Cardiaque Congestive à Yaoundé. The Journal of Medicine and Health Sciences, 17, 1-5.

[9] Zannad, F., De Ferrari, G.M., Tuinenburg, A.E., et al. (2015) Chronic Vagal Stimulation for the Treatment of Low Ejection Fraction Heart Failure: Results of NEural Cardiac TherApy foR Heart Failure (NECTAR-HF) Randomized Controlled Trial. European Journal of Heart Failure, 36, 425-433.

https://doi.org/10.1093/eurheartj/ehu345

[10] Olshansky, B., Sabbah, H.N., Hauptman, P.J. and Colucci, W.S. (2008) Parasympathetic Nervous System and Heart Failure Pathophysiology and Potential Implications for Therapy. Contemporary Reviews in Cardiovascular Medicine, 118, 863-871. https://doi.org/10.1161/CIRCULATIONAHA.107.760405

[11] Butler, J., Casey, D.E., Drazner, M.H., Fonarow, G.C., Geraci, S.A., Horwich, T., et al. (2013) 2013 ACCF/AHA Guideline for the Management of Heart Failure : Executive Summary. Journal of Antimicrobial Chemotherapy, 62, 1495-1539. https://doi.org/10.1016/j.jacc.2013.05.020

[12] Weimer, L.H. (2010) Autonomic Testing: Common Techniques and Clinical Ap- 
plications. The Neurologist, 16, 215-222. https://doi.org/10.1097/NRL.0b013e3181cf86ab

[13] Saul, J.P., Arai, Y., Berger, R.D., et al. (1988) Assessment of Autonomic Regulation in Chronic Congestive Heart Failure by the Heart Rate Spectral Analysis. American Journal of Cardiology, 61, 1292-1299. https://doi.org/10.1016/0002-9149(88)91172-1

[14] Casolo, G., Balli, E., Taddei, T., Amuhasi, J. and Gori, C. (1989) Decreased Spontaneous Heart Rate Variability on Congestive Heart Failure. American Journal of Cardiology, 64, 1162-1167. https://doi.org/10.1016/0002-9149(89)90871-0

[15] Guzzetti, S., Cogliati, C., Turiel, M., Crema, C., Lombardi, F. and Malliani, A. (1995) Sympathetic Predominance Followed by Functional Denervation in the Progression of Chronic Heart Failure. European Heart Journal, 16, 1100-1107. https://doi.org/10.1093/oxfordjournals.eurheartj.a061053

[16] Musialik-Łydka, A., Sredniawa, B. and Pasyk, S. (2003) Heart Rate Variability in Heart Failure. Kardiologia Polska, 58, 10-16.

[17] Nolan, J., Flapan, A.D., Capewell, S., MacDonald, T.M., Neilson, J.M. and Ewing, D.J. (1992) Decreased Cardiac Parasympathetic Activity in Chronic Heart Failure and Its Relation to Left Ventricular Function. British Heart Journal, 67, 482-484. https://doi.org/10.1136/hrt.67.6.482

[18] Huikuri, H.V., Ylitalo, A., Pikkujämsä, S.M., et al. (1996) Heart Rate Variability in Systemic Hypertension. American Journal of Cardiology, 77, 1073-1077. https://doi.org/10.1016/S0002-9149(96)00135-X

[19] Vinik, A.I., Maser, R.E., Mitchell, B.D. and Freeman, R. (2003) Diabetic Autonomic Neuropathy. Seminars in Neurology, 23, 365-372. https://doi.org/10.1055/s-2004-817720

[20] Fagard, R.H., Stolarz, K., Kuznetsova, T., et al. (2007) Sympathetic Activity, Assessed by Power Spectral Analysis of Heart Rate Variability, in White-Coat, Masked and Sustained Hypertension versus True Normotension. Journal of Hypertension, 25, 2280-2285. https://doi.org/10.1097/HJH.0b013e3282efc1fe

[21] Karason, K., Mølgaard, H., Wikstrand, J. and Sjöström, L. (1999) Heart Rate Variability in Obesity and the Effect of Weight Loss. American Journal of Cardiology, 83, 1242-1247. https://doi.org/10.1016/S0002-9149(99)00066-1 